\title{
COMPAÑÍAS DE TEATRO PROFESIONAL EN CANARIAS DURANTE LA PRIMERA DÉCADA DEL SIGLO XX
}

\author{
Salvador Martín Montenegro \\ Universidad de La Laguna \\ smartmon@ull.es
}

A Isabel

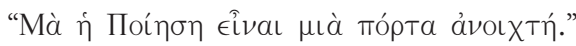

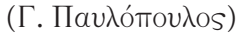

\section{RESUMEN}

En este artículo se describen algunas de las características de las compañías dramáticas profesionales que actuaron durante la primera década del siglo XX en Canarias. Se estudian, entre otros aspectos de interés, los precios, los abonos, los horarios, los elencos, los repertorios y las temporadas.

PALABRAS ClAVE: teatro español, Canarias, compañías dramáticas, temporadas teatrales, siglo XX.

\section{ABSTRACT}

«Professional Theater Companies in the Canary Islands During the First Decade of the Twentieth Century». This article describes some characteristics of professional theater companies during the first decade of the twentieth century in the Canary Islands. Prices, season tickets, performance times, casts, repertoire and theatrical seasons, among other aspects of interest, are studied.

KeY WORDS: Spanish Theatre, the Canary Islands, theater companies, theatrical seasons, $20^{\text {th }}$ century.

La actividad teatral profesional en Canarias al iniciarse el siglo XX, es decir, en el año teatral 1900-1901, comenzó bajo el signo de la incertidumbre, porque sobre los aficionados flotaba el recuerdo cercano de los problemas que habían rodeado la estancia de la modesta compañía de zarzuela del Sr. Laguna la temporada anterior, que no solo estaba en cuadro cuando se presentó el 9 de enero de 1900 en el Teatro Tirso de Molina de Las Palmas de Gran Canaria, sino que tras una interpretación desastrosa tuvo que suspender antes de tiempo sus representaciones dejando a deber a los abonados el dinero de las obras no ejecutadas; deuda que puede ser que no cobraran (Sección de noticias, 1900, marzo 13), pues la agrupación, tras una actuación también accidentada en Tenerife, abandonó las islas al poco tiempo. Sin embargo, 
lo malo, con serlo, no era que la temporada se interrumpiera bruscamente, sino que los espectadores veían como pasaban los meses y los teatros permanecían vacíos, por lo que crecía en ellos el temor de que la nueva temporada terminara como había empezado, sin compañías. Esta inquietud, que convertida en pesimismo crecía en proporción a la sequía teatral y a la salmodia periodística, que culpaba de la situación al público por su inconstancia y a los empresarios por su falta de iniciativas, felizmente terminó el 12 de marzo de 1901, para no verse interrumpida durante toda la década, con el debut de la compañía dramática de Julia Cirera en el Tirso de Molina de Las Palmas con Mancha que limpia de José Echegaray. Con ello se revelaba una vez más que, salvo momentos puntuales, el espectáculo teatral profesional no era en las islas una "planta exótica", como la prensa se apresuraba a repetir en los periodos de ausentismo del público elevando así a general un hecho particular. Al contrario, el teatro era un espectáculo estable, cuya presencia y frecuencia era proporcional al público posible, a la existencia de numerario y a los espacios dramáticos existentes. Son precisamente las sucesivas temporadas teatrales de este periodo decenal, y las compañías dramáticas profesionales que las hacen posible, lo que se estudia de forma general en el presente artículo. Se elude el análisis de las compañías y de los artistas de variedades, así como la actividad dramática de los grupos amateurs.

Aunque, como es sabido, el año oficial comenzaba a principios de septiembre, la temporada dramática en el Archipiélago era normal que se iniciara entrado el otoño para evitarle, se decía, incomodidades al público por los rigores del calor. La actividad teatral anual se distribuía en dos grandes periodos, la temporada de otoño y la de primavera. Los datos con los que contamos para la primera década del siglo XX confirman este patrón, pues salvo la temporada 1900-01, que se demoró en exceso, y la 1907-08 que se abrió el 5 de septiembre, las restantes comenzaron en dicha estación. Si tenemos en cuenta la fecha en que se presenta la primera compañía en las islas, vemos que la mayoría lo hace en octubre o noviembre. En cambio, si lo que tomamos en consideración es el cierre de la temporada, notamos que las últimas agrupaciones que nos visitan finalizan sus representaciones entre finales de invierno y finales de primavera, salvo cuatro que lo hacen en verano:

\begin{tabular}{|l|l|l|l|}
\hline \multicolumn{2}{|l|}{ Inicio de temporada, mes } & \multicolumn{3}{l|}{} \\
\hline $1900-1$, marzo & $1901-2$, octubre & $1902-3$, noviembre & $1903-4$, diciembre \\
\hline $1904-5$, octubre & $1905-6$, octubre & $1906-7$, octubre & $1907-8$, septiembre \\
\hline $1908-9$, noviembre & $1909-10$, noviembre & & \\
\hline
\end{tabular}

Porcentaje: $80 \%$ = octubre $(4,40 \%)$, noviembre $(3,30 \%)$, diciembre $(1,10 \%) .20 \%=$ marzo (1, 10\%), septiembre $(1,10 \%)$.

\begin{tabular}{|l|l|l|l|}
\hline \multicolumn{2}{|l|}{ Final temporada, mes } & \multicolumn{2}{l|}{} \\
\hline $1900-1$, junio & $1901-2$, agosto & $1902-3$, junio & $1903-4$, julio \\
\hline $1904-5$, febrero & $1905-6$, marzo & $1906-7$, julio $^{2}$ & $1907-8$, agosto $^{3}$ \\
\hline $1908-9$, marzo & $1909-10$, marzo & & \\
\hline
\end{tabular}

Porcentaje: $\mathbf{6 0} \%=$ marzo $(3,30 \%)$, febrero $(1,10 \%)$, junio $(2,20 \%) .40 \%=$ julio $(2,20 \%)$, agosto $(2,20 \%)$. 
Las especiales características del circuito teatral canario obligaban a las empresas a abrir una nueva temporada en cada una de las islas donde existía una demanda más o menos constante: Tenerife, Gran Canaria y La Palma. Generalmente, la inauguración del año teatral se adelantaba o retrasaba en cada isla, aunque mejor sería decir en cada una de las capitales de las islas citadas, dependiendo de la ciudad en la que comenzaba sus representaciones la primera compañía que llegaba al Archipiélago. No fue habitual que dos compañías diferentes actuaran a la vez en dos islas distintas abriendo o cerrando en cada una el año teatral.

Durante la década actuaron en Canarias diecinueve compañías profesionales, aunque dos de ellas, la de Pablo López y los restos de la de Ricardo Calvo, representaron dos temporadas seguidas, como puede confirmarse en el siguiente cuadro, que contiene el año teatral, el nombre de la compañía y el lugar en que debuta:

\begin{tabular}{|l|l|l|}
\hline TEMPORADA & \multicolumn{1}{|c|}{ COMPANIÍA } & \multicolumn{1}{|c|}{ LUGAR } \\
\hline $1900-1901$ & 1) Cía. de Julia Cirera & GC \\
\hline $1901-1902$ & $\begin{array}{l}\text { 2) Cía. de Antonio Paso } \\
\text { 3) Cía. de Pablo López }\end{array}$ & GC \\
\hline $1902-1903^{*}$ & $\begin{array}{l}\text { Cía. de Pablo López } \\
\text { 4) Cía. de Sánchez de León } \\
\text { 5) Cía. de Emilio Thuillier }\end{array}$ & TF \\
\hline $1903-1904$ & $\begin{array}{l}\text { 6) Cía. de ópera de Ricardo Villa } \\
\text { 7) Cía. cómico-dramática de Aranaz-Echaide }\end{array}$ & GC \\
\hline $1904-1905$ & 8) Cía. de zarzuela de Bonoris-Duval \\
\hline $1905-1906^{*}$ & $\begin{array}{l}\text { 9) Cía. dramática de Donato Jiménez } \\
\text { 10) Cuadro de zarzuela de Rafael Alaria }\end{array}$ & GC \\
\hline $1906-1907$ & $\begin{array}{l}\text { 11) Cía. de ópera de Giovannini } \\
\text { 12) Cía. de Ricardo Calvo* } \\
\text { 13) Cía. de Manuel Espejo } \\
\text { 14) Cía. de García-Nieva }\end{array}$ & GF \\
\hline
\end{tabular}

${ }^{1}$ La última función que nos consta de la Cía. de Donato Jiménez es del 31-3-1906. Desconocemos si siguió actuando en abril.

${ }^{2}$ La Cía. de García-Nieva inició sus actuaciones en Lanzarote en junio de 1907, puede ser que las continuara durante algunos días de julio (Los que viajan, 1907, julio 13).

${ }^{3}$ Nieva y su compañía zarparon de Las Palmas de Gran Canaria en el vapor Reina Victoria el 25 de agosto para la Península (Los que viajan, 1908, agosto 25).

${ }^{4}$ También citada como Cía. de Jiménez-Morano.

5 Procedía de la Cía. de Calvo. Debutó en el Circo Cuyás de Las Palmas de Gran Canaria el 9-1-1907 (Espectáculos, 1907, enero 10) y se despidió de su publicó el 7-3-1907 (En el Circo, 1907, marzo 6).

${ }^{6}$ Procedía de la Cía. de Manuel Espejo. También se le cita como Cía. de Nieva.

${ }^{7}$ El 10 de marzo, el primer actor cómico Manuel Espejo, el Sr. Aguado y los artistas hermanos Gómez Ferrer embarcaron para Cádiz con lo que desapareció la Cía. de Espejo. La prensa informó que el resto del cuadro dramático seguiría sus representaciones en Arucas (Sección de noticias, 1907, marzo 10) y en Tenerife. La nueva agrupación debutó en S. C. de Tenerife el 21 de marzo en el teatro de la Sociedad Filarmónica (Espectáculos, 1907, marzo 22). 


\begin{tabular}{|l|l|l|}
\hline $1907-1908$ & $\begin{array}{l}\text { Cía. de García-Nieva } \\
\text { 15) Cía. de zarzuela de Valentín González } \\
\text { 16) Cía. de Enrique Borrás }\end{array}$ & $\begin{array}{l}\text { GC } \\
\text { GC }\end{array}$ \\
\hline 1908-1909* & $\begin{array}{l}\text { 17) Cía. cómico-lírica de Miguel Soler } \\
\text { 18) Cía. dramática de Carmen Cobeña }\end{array}$ & GC \\
\hline $1909-1910$ & 19) Cía. de zarzuela de Salvador Orozco & TF \\
\hline
\end{tabular}

Si tenemos en cuenta la fecha de llegada de las primeras compañías, se constata que la presentación de los cómicos ante el público canario se produjo primero en Las Palmas de Gran Canaria y no en Santa Cruz de Tenerife. Resulta evidente que durante casi toda la década la capital de Gran Canaria funcionó como pórtico de entrada de las compañías que hacían giras por el Archipiélago.

En el cuadro anterior, las fechas con asteriscos corresponden a temporadas en las que el año teatral en cada isla lo inauguró una compañía que no había actuado antes en la otra. Así, en 1902-03, el primer cuadro dramático, que fue el de Pablo López, debutó a principios de noviembre en S. C. de Tenerife, donde se mantuvo hasta el 10 de enero cuando se dirigió a Gran Canaria (Crónica, 1903, enero 9). En Las Palmas de G. C., la temporada se abrió en diciembre con una compañía distinta, la Sánchez de León, que estuvo hasta mediados de enero cuando paso a Tenerife. En 1905-06, se da la circunstancia, poco habitual, de que una compañía inaugure la temporada en una isla y al terminar su actividad no la continúe en ninguna otra. Este es el caso del Cuadro de zarzuela de Alaria, que se presentó ante el público en noviembre de 1905 en Santa Cruz de Tenerife en el teatro de la Sociedad Filarmónica (La Filarmónica. Cuadro de zarzuelas, 1905, noviembre 22) y tras actuar en el Teatro Principal, y de nuevo en la Filarmónica, pasó al Puerto de la Cruz y La Orotava donde finalizó definitivamente sus representaciones por dificultades surgidas con la empresa. Se embarcó para Sevilla en el Hespérides a finales de febrero de 1906 (Crónica general. Artistas, 1906, febrero 26). En Gran Canaria, esa misma temporada comenzó con la llegada en octubre de la compañía de Donato Jiménez, que al acabar su cometido sí se trasladó a Tenerife. En la temporada 1908-09 debutó en Tenerife la de Cobeña y en Gran Canaria la cómico-lírica de Miguel Soler, ambas habían llegado en noviembre de 1908 y se despidieron en marzo y febrero, respectivamente, de 1909. Otro caso interesante, aunque distinto, pues no era la primera compañía del año y, además, se encontró ante una situación imprevista, fue el de la agrupación de Ricardo Calvo que, después de terminar sus actuaciones en Gran Canaria a principios de 1907, no viajó, como era habitual, a Tenerife por la epidemia de tifus que se padecía en su capital. La compañía siguió actuando en Las Palmas de G. C. hasta marzo del mismo año, pero bajo otro nombre, el de uno de sus actores, Manuel Espejo.

${ }^{8}$ Orozco, por motivos de salud, embarcó para la Península en febrero y fue sustituido en la dirección de la compañía por Emiliano Latorre (Teatro, 1910, febrero 24). 
La duración de la estancia en las islas de estas agrupaciones superó o rondó los dos meses y la mayoría traspasó esta barrera con una permanencia de 3, 4 o 5 meses e incluso, v. gr., la Cía. de Nieva, rebasando el año. En cuanto al número anual de compañías, oscila entre uno y cuatro. El hecho de que dos de las tres temporadas con una sola compañía se dé al comienzo y al final del periodo que estudiamos hizo que el público percibiera estos años como una buena década teatral:

\begin{tabular}{r|l}
\hline \multicolumn{2}{|c}{ Número de compañías por temporada } \\
\hline n. $^{\circ}$ & Temporadas \\
\hline 1 & $(1900-01),(1904-05),(1909-10)$ \\
\hline 2 & $(1901-02),(1903-04),(1905-06),(1908-09)$ \\
\hline 3 & $(1902-03),(1907-08)$ \\
\hline 4 & $(1906-07)$ \\
\hline
\end{tabular}

Esta situación no solo se consolidó, sino que se vio reforzada en la siguiente década, en la que visitaron las islas más de 30 compañías profesionales. Este aumento fue progresivo, pues se pasó de la presencia de dos agrupaciones en la temporada 1910-11 a cuatro en 1911-12 y a siete en 1912-13 y 1913-14. La tendencia se ralentizaría durante la 1. ${ }^{a}$ Guerra Mundial, aunque no de forma excesiva, pues el número se mantuvo entre dos y cinco con la sola excepción de la temporada 1918-1919 en que únicamente recaló por estas tierras un grupo. Los teatros, como fácilmente se deduce de las cifras anteriores, estuvieron activos durante más tiempo; pero, por contra, la duración de la estancia de las compañías disminuyó al poco de iniciarse la década, a partir de la llegada en enero de 1913 de la Cía. de ComendadorMontenegro.

Es bien sabido que las islas Canarias se beneficiaron de su situación como lugar de paso de muchos grupos o artistas que iban de tournée a América o regresaban de ese continente con destino a Europa. Sin embargo, no se debe generalizar, pues no fueron tantas como se cree las compañías teatrales que actuaron aquí como resultado de esta ventajosa posición en la ruta transatlántica. Si bien es cierto que en la segunda década del siglo XX recalaron de este modo siete troupes (Cía. de Rosario Pino, Cía. juvenil italiana de Arnaldo Billaud, Cía. de Xirgu-Thuillier, Cía. de Matilde Moreno, Cía. de Ramón Caralt, Cía. de Mercedes Pérez y Cía. de Luis Echaide) y que tres más tuvieron como destino u origen Madeira (Cía. de Italia Vitaliani-Duse, Cía. de Enrique Beut y Cía. de Pablo López); en esta década que comentamos casi todas las agrupaciones que actuaron llegaron de la Península y al

9 La compañía de Calvo actuó durante mes y medio, pero si la consideráramos como una sola con la de Manuel Espejo, la estancia superaría los tres meses. 


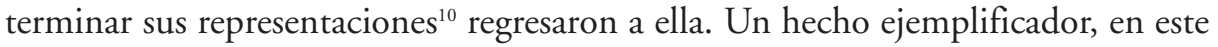
sentido, lo encontramos en la compañía dramática dirigida por Francisco Tressols, que de paso para La Habana llegó a S. C. de Tenerife en octubre de 1902. Pretendía dar algunas representaciones, que no pudo llevar a cabo por la aplicación de las disposiciones gubernativas que prohibían abrir los teatros que no estuvieran en condiciones de seguridad contra los incendios (Crónica. Teatral, 1902, octubre 18). De hecho, la autoridad gubernativa prohibió la función que la compañía trató de dar el 22 de octubre en La Laguna (Crónica, 1902, octubre 23).

La excepción la encontramos en los casos de la Cía. de Espejo, nacida de la de Ricardo Calvo, y la Cía. de García-Nieva, que surge de la disolución de la de Espejo en marzo de 1907, que actuó, según nuestros datos, hasta su embarque en Santa Cruz de Tenerife para la Península a finales de agosto de 1908, por lo menos en Arucas, Gáldar, Las Palmas de Gran Canaria, Arrecife de Lanzarote, S. C. de Tenerife, La Laguna, La Orotava, Icod, S. C. de La Palma y Los Llanos de Aridane. Esto resulta sumamente indicativo, pues nos apunta a dos hechos importantes, primero, el convencimiento por parte de los empresarios foráneos, que montaban las compañías, de que las islas seguían siendo un circuito teatral rentable y, segundo, la presencia y pervivencia en Canarias de iniciativas empresariales (José Zamorano Villar, Gundemaro Baudet, José Santaella, José Curbelo...), que de una forma u otra aseguraron, con todo los altibajos que se quiera, la continuidad de los espectáculos dramáticos. En este sentido, bastante claro lo tenía el periodista grancanario Francisco González Díaz cuando afirmaba que el público isleño parecía creer que no tenía derecho a ser muy exigente con los actores, convencido de que las compañías al abandonar la Península para actuar en Canarias realizaban un acto en contra de sus intereses económicos y que por ello se le debía gratitud, que convertíamos en condescendencia:

Y estas circunstancias nuestras explican, además, porque somos tan benévolos con la gente de teatro, porque le dispensamos una indulgencia rayana en la debilidad, encontrando defensa ó atenuación de defectos hasta para aquellos actores que no pasan por tales en parte alguna.

Estamos convencidos de que no tenemos derecho á ser muy exigentes; opinamos que las compañías escénicas al abandonar la Península y emprender un viaje á Canarias, realizan un acto contra sus intereses y con él obligan nuestra gratitud.

Estos son puntos de vista erróneos, pues las compañías excusarían venir á nuestra tierra si no les alentasen el ejemplo de otras que antes vinieron y regresaron satis-

${ }^{10}$ La agrupación de Pablo López tras terminar sus actuaciones en Gran Canaria se trasladó, a principios de febrero de 1902, a la isla de Madeira y no a Tenerife como era habitual. El empresario alegaba, de forma no muy convincente, que este cambio se debía, entre otras razones, al presumible cansancio del público tinerfeño tras la campaña de la compañía de Antonio Paso. Terminado su contrato en la isla portuguesa se presentó en S. C. de Tenerife en el Teatro Principal el 1-4-1902 donde causó una buena impresión con Marina y El barbero de Sevilla. 
fechas. Vienen animadas por la confianza de hacer negocio, y casi siempre lo hacen. Encuentran, por colmo de satisfacciones, un público que no sólo se muestra indulgente, sino que se revela también hasta cierto límite entendido é ilustrado. (1905, noviembre 4).

Como ya hemos indicado, fue poco habitual que las compañías actuaran solo en una isla por lo que la duración de las estadías y, por consiguiente, de las temporadas en Tenerife y Gran Canaria fue generalmente proporcional. A esta sostenibilidad coadyuvó la posibilidad de extender las representaciones a aquellas poblaciones del interior que podían asegurar un abono mínimo a las empresas. En el caso de Tenerife, la irradiación geográfica de los grupos teatrales siguió normalmente el eje La Laguna, La Orotava, Puerto de la Cruz e Icod. Durante la primera década del siglo XX se mantiene esta situación, pues más del $60 \%$ de las compañías representaron en una o más de estas localidades. En Gran Canaria esta irradiación fue menor, por lo menos el 35\%, pues se limita, según nuestros datos, a Arucas y Gáldar. Sin embargo, este porcentaje sería más alto si se tuviera en cuenta en el cómputo el barrio del Puerto de la Luz de Las Palmas de Gran Canaria, que desde este punto de vista funcionaba como una población independiente como lo era, por ejemplo, la ciudad de La Laguna en Tenerife.

A lo largo de la temporada, algunos cuadros escénicos modificaron su elenco con la entrada o salida de artistas. Los cambios, al parecer, más significativos los encontramos en la compañía García-Nieva, que se reforzó para la campaña 1907-08 con algunos comediantes contratados en la Península (Sección de noticias, 1907, noviembre 26; Crónica general. Teatral, 1907, diciembre 4; Crónica general. De teatros, 1907, diciembre 5; Crónica general. Viajeros, 1907, diciembre 10; Crónica general. Teatro principal, 1908, mayo 5), y la compañía de Pablo López que de la misma forma lo hizo para la temporada 1902-03 (Teatral, 1902, octubre 28).

De las otras islas tenemos evidencias de la existencia de representaciones en Lanzarote ${ }^{11}$ y en La Palma, que mantiene su condición de tercera isla en lo que respecta al movimiento teatral, si bien durante este periodo no podemos hablar de temporadas sino de actuaciones aisladas de algunas compañías o de temporadas parciales. De hecho, solo nos constan actuaciones teatrales profesionales en Santa Cruz de La Palma en 1903 (visita en abril y mayo de la Cía. de Sánchez de León), en junio de 1907 y de enero a marzo de 1908 (Sección de noticias, 1908, enero 11; Varias noticias, febrero 26; Por la Provincia. De La Palma, marzo 14; Varias noticias, marzo 27) por los artistas de la compañía de García-Nieva, que también actuaron en junio de 1907 en Los Llanos de Aridane (Hernández, 2001, agosto 5):

${ }^{11}$ Las funciones de las que estamos seguros las llevó a cabo la compañía de García-Nieva en Arrecife de Lanzarote en julio de 1907 (El corresponsal, 1907, julio 27; Los que viajan, 1907, julio 13) y en mayo-junio de 1908 (A. R., 1908, mayo 18, mayo 29, junio 6, junio 22, junio 30). 
Entre 1906 y 1924, visitaron el Salón Teatro Aridane varias compañías desplazadas casi siempre de Santa Cruz de La Palma en donde a la sazón se encontraban actuando. Así en enero de 1907 se alquila el salón a una compañía de Zarzuela "que actúa en S/C de La Palma». El 21 de junio de 1907, la compañía cómico dramática de $\mathrm{D}^{\mathrm{a}}$. Carmen García y D. Enrique Nieva representan las obras El gran galeoto, de José Echegaray y Los corridos, juguete cómico de Ramón Marsall. Esta compañía venía también de S/C de La Palma en donde había puesto en escena, en el Teatro Chico, un repertorio mucho más amplio: D. Álvaro o la fuerza del Sino, El genio alegre, Tierra Baja, entre otras obras. En 1913 actúa la compañía infantil "Hermanos Pombo"; en 1916 la compañía "Rosales" y la compañía o dueto "Mari-Guerri"; en 1921, el dueto "Sres. Ronsel”. (Hernández Bravo, 2005: 250).

Parece que no vino la compañía de Carmen Cobeña, porque "el abono que se abrió entre diciembre del año 1908 y enero de 1909 para traerla, no llegó a cubrirse" (Rey y Abdo, 1984, 26).

La afición del público isleño por las obras y los espectáculos lírico-dramáticos resulta evidente solo con echar una rápida mirada a la cartelera teatral del periodo. Esta tendencia, que había tomado un gran impulso a finales de la centuria anterior se mantuvo durante estos y los siguientes años con fuerza, manifestando así su gran vitalidad. Como indica Castro Brunetto para Tenerife, "correspondiéndose con el auge de la zarzuela en la Península a finales del siglo XIX, este espectáculo musical cobró $[. .$.$] una pujanza sin precedentes, no decayendo hasta mediar el presente siglo$ [s. XX]. Entre 1900 y 1931 arribaron a las costas santacruceras numerosas compañías" (1990: 53) de este tipo. No nos debe extrañar que casi la mitad de las compañías que nos visitaron durante las diez primeras temporadas tuvieran este carácter y que, salvo excepciones, cada año teatral contara como mínimo con una troupe de esta naturaleza.

Incluso en dos de las tres temporadas con una única agrupación en los escenarios, las dos compañías presentes eran lírico-dramáticas: 1904-05 (Cía. BonorisDuval) y 1909-10 (Cía. de Salvador Orozco). Por otro lado, aunque no faltaron compañías de ópera, la de Villa y la de Giovannini, o grupos teatrales que intercalaban en su repertorio este tipo de piezas, se puede decir que, como expresión clara del reinado del género chico, la mayoría de los cuadros líricos dedicaron su atención a las zarzuelas en un acto o las interpolaron en su repertorio durante la temporada. Según Brunetto (p. 56), todas las compañías [de esta clase] traían en su repertorio entre cincuenta y sesenta zarzuelas (a veces más y a veces menos), interpretándolas prácticamente todas".

\begin{tabular}{|l|l|}
\hline $\begin{array}{l}\text { Compañías } \\
\text { dramáticas }\end{array}$ & $\begin{array}{l}\text { Cía. de Julia Cirera, Cía. de Sánchez de León, Cía. de Emilio Thuillier, Cía. de } \\
\text { Aranáz-Echaide, Cía. de Donato Jiménez, Cía. de Ricardo Calvo, Cía. de Manuel } \\
\text { Espejo }^{12} \text {, Cía. de García-Nieva, Cía. de Enrique Borrás, Cía. de Carmen Cobeña }\end{array}$ \\
\hline $\begin{array}{l}\text { Compañías } \\
\text { lírico-dramáticas }\end{array}$ & $\begin{array}{l}\text { Cía. de Antonio Paso, Cía. de Pablo López, Cía. de Ricardo Villa, Cía. Bonoris- } \\
\text { Duval, Cuadro de Rafael Alaria, Cía. de Giovannini, Cía. de Valentín González, } \\
\text { Cía. de Miguel Soler, Cía. de Salvador Orozco }\end{array}$ \\
\hline
\end{tabular}

${ }^{12}$ Estrenó algunas piezas lírico-dramáticas. 
En cuanto al número de integrantes de las compañías, podemos decir que, salvo excepciones, fluctuaba, si contabilizamos solo los intérpretes, y obviamos otros componentes del personal como los apuntadores, maquinistas, sastres, peluqueros, pintores, etc., entre 18 y 27 individuos con una distribución generalmente proporcional entre actores y actrices. Las agrupaciones lírico-dramáticas, salvo el Cuadro de Alaria, contaron con un elenco mucho más numeroso. Si contamos solo los cantantes y actores, los coristas y las parejas de baile su cifra está, más o menos, entre 40 y 60 componentes, si bien la mayoría del plantel lo formaban los coristas de ambos sexos. Así, por ejemplo, la compañía de Paso y la de Pablo López tenían 28, la de Valentín González 26, la de Bonoris-Duval y la de Giovannini 24. Además, a esta numerosa plantilla había que sumarle la orquesta, que en las agrupaciones de cierta importancia rondaba o superaba los 30 músicos, aunque no necesariamente tenían que pertenecer a la compañía, v. gr., la Cía. de Bonoris-Duval contaba con 40 profesores de orquesta, seis de la Península y 34 del país, y la de Giovannini tenía entre 28 y 30 , de los cuales 10 venían de la Península.

La presencia regular en los escenarios de estos dos tipos de conjuntos teatrales implicó, como es obvio, que el orden de las diferentes partes del espectáculo se diversificara, aunque básicamente podríamos hablar de funciones estructuradas alrededor de una pieza grande, como central, y las organizadas a partir de las obras en un acto. En cuanto a las primeras, la disposición más frecuente fue la tradicional división en dos, es decir, obra principal más obra corta, a modo de fin de fiesta o cierre. Este modelo, con sus variantes, fue el habitual de las compañías dramáticas presentes en la cartelera de la época; sin embargo, también algunas de zarzuela, como la de Pablo López o la de Antonio Paso, hicieron uso de este tipo de funciones intercalándolas con otras a lo largo de la temporada. Por otro lado, solo las compañías de ópera, acorde con su naturaleza, mantuvieron durante toda su estadía las veladas constituidas por una única obra "grande". En lo que hace referencia a las segundas, la organización del espectáculo siguió el modelo del teatro por horas, es decir, representaciones por secciones, generalmente tres obras en un acto separadas cada una por un intervalo. Salvo las compañías operísticas, todas las agrupaciones líricas que funcionaron durante la década, v. gr., la de Orozco o la de Alaria, se ajustaron en mayor o menor medida a este modelo tan característico, conocido y considerado por los espectadores.

Resulta notorio, por tanto, durante todo el periodo que analizamos la relevante presencia de compañías que hacen uso de la fórmula bien acreditada del teatro por horas, cuya existencia en los escenarios canarios está confirmada desde finales del siglo anterior. Sin embargo, este modelo parece que resultaba de algún modo poco eficaz cuando el público posible, sobre todo el habitual, era siempre el mismo. Para contribuir a los intereses de los abonados y, por ende, del empresario se suele combinar esta fórmula con otra muy cercana, pero más funcional, en la que se mantienen las secciones, pero con una única entrada para todas durante toda la temporada para los abonados. De este modo, se salvaguarda el intocable sistema de abono, tan necesario para la sobrevivencia de las compañías. Tal vez estos inconvenientes y otros, relacionados con el cansancio de los espectadores por una fórmula agotada por reiteración, sean la causa de que, siguiendo la tendencia general de declive del teatro por 
secciones, esté poco presente en las islas desde la $2 .{ }^{\text {a }}$ década del siglo XX la receta del teatro por horas.

El número de funciones por abono por compañía en cada uno de los teatros principales de las dos islas "centrales" fluctuó habitualmente entre 20 y 40, aunque encontramos casos, como el del grupo de Donato Jiménez y el de Antonio Cano, en los que se alcanzaron las 50 representaciones. Atendiendo al número de sesiones programadas, y para permitir un pago más desahogado, los abonos se solían segmentar: $20+20,25+10,15+15,15+5,15+15+10$, etc. El modo de pago, dentro de unos límites, variaba según la compañía; así, por ejemplo, la troupe de Paso (Crónica, 1901, noviembre 16) lo cobraba por decenas anticipadas ${ }^{13}$, la de Valentín González (La temporada teatral, 1907, septiembre 2) en dos plazos anticipados y en dos series de 20 funciones $^{14}$; y la de Borrás (Teatrales. La compañía de Borrás, 1908, enero 4) ${ }^{15}$ y la de Cobeña (La compañía dramática de Carmen Cobeña, 1909, enero 11) ${ }^{16}$ en dos plazos, el primero al inscribirse y el segundo en la décima función. Se entendía que el abonado quedaba comprometido al pago de la totalidad de las representaciones.

Como es obvio, en las pequeñas poblaciones cuando el número de funciones aconsejaba el abono, este, por el reducido número de representaciones, no se fraccionaba. Normalmente, el abono podía ser adquirido con bastante antelación y hasta días antes, e incluso el mismo día, del debut y no solía incorporar, aunque encontramos algunas compañías que lo hacen, las funciones extraordinarias como, entre otras, las de beneficio, la de tarde, las "de moda" o las sesiones "vermouth". En general, la prensa casi siempre desaconsejó a las empresas este tipo de funciones fuera de abono, salvo las de beneficio, las benéficas, las de autores del país, etc., aunque se le hiciera a los abonados rebajas, precios acomodados o especiales, porque nunca habían arraigado aquí. Fue costumbre reservar a los abonados de la anterior temporada el nuevo abono para permitir que estos no perdieran sus localidades y para que las empresas pudieran iniciar su andadura con ciertas garantías. Las localidades que con más frecuencia formaban parte del abono eran las más caras, es decir, la platea, los palcos y las butacas $^{17}$. En el precio de la entrada no se solía incluir el timbre, que corría a cargo del público. La diferencia de precios entre una entrada con abono y otra sin él era más o menos del $25 \%$. Por otro lado, los precios de las localidades variaban dependiendo de si se incluía o no la entrada, que en la década, salvo excepciones, estaba entre 0,75 pts. y 1 pts. para la general y entre 0,75 pts. y 1,1 pts. para palcos y paraíso. También podía sufrir alteraciones el precio según el tipo de compañía (zarzuela, ópera, drama), de

${ }^{3}$ Abono por 50 funciones.

${ }^{14} \mathrm{Abono}$ por 40 funciones.

${ }^{15}$ En Santa Cruz de Tenerife, la empresa cobró el segundo plazo en la primera función (De teatro. La compañía de Borrás, 1908, febrero 12). Abono por 20 funciones.

${ }^{16}$ Abono por 20 funciones.

${ }^{17}$ No es de extrañar que la empresa de la Cía. de Enrique Borrás fuera multada en su debut con 50 pts. por el delegado gubernativo por añadir sillas a las filas de butacas (Sección de noticias, 1908, enero 20). 
obra o de función, la calidad del grupo teatral, el aforo del teatro, etc. En general, los precios se mantuvieron en unos valores parecidos, si bien los de las compañías de ópera eran un poco más altos, aunque relativamente módicos, según la prensa. La empresa se reservaba el derecho de aumentar los precios en las obras que creyera oportunas, si bien respetando, generalmente, el de los abonados.

A modo de muestra, podemos fijar nuestra atención en los precios de las butacas, aunque teniendo en cuenta que los datos con los que contamos son limitados. Como puede comprobarse en el cuadro que sigue, si dejamos a un lado determinados casos, como, por ejemplo, los de las compañías de ópera, o las secciones del teatro por horas, los precios oscilan, con entrada, entre 2 y 3 pesetas con abono y entre 2,5 y 3,75 pesetas sin él.

\begin{tabular}{|c|c|c|c|c|c|}
\hline Compañía & Localidad & Abono LPG & diario & Abono SCT & diario \\
\hline Cía. Cirera & Butacas c/e & & & 2 & 2,5 \\
\hline Cía. A. Paso (z) & Butacas & 2 & 2,5 & 2,5 & 3 \\
\hline Cía. Sánchez León & Butacas c/e & & & 2 & 2,5 \\
\hline Cía. E. Thuillier & Butacas c/e & & & 2,5 & $3 / 4^{18}$ \\
\hline \multirow[t]{2}{*}{ Cía. Villa (o) } & Butacas & 3 & 4 & & \\
\hline & Butacas c/e & & & 4 & 5 \\
\hline \multirow[t]{2}{*}{ Cía. Aranaz-Echaide } & Butacas s/e & 1,25 & 2 & & \\
\hline & Butacas c/e & & & 2 & 2,5 \\
\hline Cía. Alaria (z) & Butacas c/e & & & & $0,6($ secc., c/t $)$ \\
\hline \multirow[t]{2}{*}{ Cía. Donato-Jiménez } & Butacas s/e & 1,75 & 1,25 & & \\
\hline & Butacas c/e & & & 2 & 2,5 \\
\hline \multirow[t]{2}{*}{ Cía. Giovaninni (o) } & Butacas s/e & 3 & & & \\
\hline & Butacas & & & 3 & 4 \\
\hline Cía. García-Nieva & Butacas $c / \mathrm{e}^{19}$ & & & $2(\mathrm{c} / \mathrm{t})$ & $2,5(\mathrm{c} / \mathrm{t})$ \\
\hline \multirow[t]{2}{*}{ Cía. Borrás } & Butacas s/e & 2,2 & 2,75 & & \\
\hline & Butacas c/e & & & 2,75 & 3,75 \\
\hline \multirow[t]{3}{*}{ Cía. V. González (z) } & Butacas c/e & 2,25 & 2,75 & & \\
\hline & Butacas c/e & 2,75 & & & 1 (secc.) \\
\hline & Butacas c/e & & & 3 & 3,5 \\
\hline \multirow[t]{3}{*}{ Cía. Cobeña } & Butacas s/e & 2 & 2,5 & & \\
\hline & Butacas c/e & & & 2,5 & 3 \\
\hline & Butacas c/e $\mathrm{e}^{20}$ & & & 2 & 2,5 \\
\hline \multirow[t]{2}{*}{ Cía. Orozco (z) } & Butacas c/e & & & $2,2(\mathrm{c} / \mathrm{t})$ & \\
\hline & Butacas c/e $\mathrm{e}^{21}$ & & & & $1,1($ secc., c/t $)$ \\
\hline
\end{tabular}

* cle: con entrada; c/t: con timbre; s/e: sin entrada; secc.: sección; o= ópera; z= zarzuela.

${ }^{18}$ En dos funciones especiales.

${ }^{19}$ Abono por 10 funciones en el Teatro Viana de La Laguna.

${ }^{20}$ Cinco funciones. Precios rebajados.

${ }^{21}$ Incluye el timbre. 
La venta de los abonos, además de en la contaduría del teatro, se realizaba en locales y negocios bien conocido y abiertos al público. Algunos de ellos son los que siguen: en Santa Cruz de Tenerife, la cervecería Las Cuatro Naciones de Claudio Gaspar, la tabaquería Las Canarias de José Zamorano Villar, Salón Modas de José Martínez Simó, tabaquería del Sr. Carrillo, y en el establecimiento de ultramarinos de Miguel Feria; en Las Palmas de Gran Canaria, Café de Madrid, casa de comercio de Pantaleón Quevedo Hermanos y Salón Novedades; y en La Laguna, establecimiento de Casiano Corona. En cuanto a la publicidad de las compañías se hacía, siguiendo la costumbre, antes de la llegada de los cómicos y durante sus representaciones a través de la prensa (crítica, información, publicidad), el reparto de programas, anuncios y prospectos, la exposición de los retratos de los artistas y la cartelería.

Las funciones normales comenzaban a las 8:00 u 8:30, mientras que las habituales tres secciones del teatro por horas solían empezar la $10^{a}$ entre las $7: 00^{22}$ y las 8:00, la 2. ${ }^{\mathrm{a}}$ entre las 9:00 y las 9:30, y la $3 .^{\mathrm{a}}$ entre las 10:00 y las 11:00. Podemos encontrar sesiones de tarde, "vermouth" o matiné entre las 3:30 y las 5:30, tanto en las funciones por sección como en las normales, aunque generalmente se aconseja, salvo costumbre o excepción, como, por ejemplo, los domingos, no abusar de ellas. Tradicionalmente no se acostumbraba a representar los lunes y los viernes, aunque algunas compañías recurrían a esos días para las sesiones extraordinarias, para desarrollar el total de sesiones programadas o para actuar en otras poblaciones o teatros. Las funciones debían acabar, como quedaba recogido en el artículo 17 del Reglamento de policía y espectáculos de 2-8-1886 ${ }^{23}$, antes de las $12: 30$ bajo pena de multa. Esto fue lo que le ocurrió por dos veces a la agrupación de zarzuela de Valentín González en Santa Cruz de Tenerife, a la que el gobernador Santos Ecay sancionó en su debut con 50 pts. (Varias noticias, 1907, diciembre 23) y en el estreno de El pollo Tejada con 100 pts. más con apercibimiento de ponerle 500 pts. si reincidía (Fray Gerundio, 1908, febrero 1).

Aunque las compañías usaban los decorados de los teatros en los que actuaban, con sus conocidas limitaciones e impropiedades ${ }^{24}$, un buen número de ellas, como, v. gr., las de Paso, Thuillier, V. González, Donato Jiménez, Borrás, Cobeña y Orozco, traían sus propios decorados para todas o parte de las representaciones, lo que suponía, junto al anuncio de un vestuario y atrezzo escogido y apropiado, un reclamo importante para los espectadores y abonados y una más que posible garantía de éxito. A este indiscutible atractivo se unía el de la calidad de la troupe y el de sus

${ }^{22}$ Se desaconsejaba dar diariamente secciones "a esa hora, porque el más y el que menos, todos estarán en la comida”.

${ }^{23}$ Además de este reglamento eran de cumplimiento la RO de 13-5-1882, el Reglamento de 27-10-1885 y la RO de 23-4-1902.

${ }^{24}$ Un ejemplo que ilustra bien esta cuestión es el que protagoniza el Ayuntamiento de S. C. de Tenerife, que, consciente del problema, adquirió por 2500 pts. de la compañía de Francisco Tressols, que se encontraba de paso, 30 decoraciones con la que sustituir "a muchas de las que hasta ahora venían usándose con notable perjuicio de la más elemental estética” (Crónica. Teatral, 1902, octubre 27). 
primeras figuras. La información publicitaria difundida antes del debut de los grupos insistía en este aspecto haciéndose eco de la solidez y brillantez de la compañía, y de la reputación de sus más conspicuos intérpretes, que eran bien conocidos por el público y la prensa por su labor en los teatros peninsulares o por su presencia en las islas en anteriores temporadas. Son los casos, entre otros, de los intérpretes Enrique Borras, Emilio Thuillier y Francisco Morano, cuyos nombres eran de por sí un seguro aval, "que formaban la trinidad de grandes actores de aquel principio de siglo tan pródigo en figuras cumbres en todas las manifestaciones del arte escénico" (Martínez Viera, 1968: 227); de Enrique Sánchez de León del que el público recordaba la magnífica actuación que su compañía realizó en 1899; de Pablo López, popularísimo en nuestras islas y formador siempre de magníficas compañías, que nos visitó cuatro veces desde 1895 (Martínez Viera, 1968: 183-188), y de Manuel Espejo, que ya había estado aquí formando compañía en 1894, 1895 y 1899 (Luzardo Cabrera, 2015). Además de estos factores citados, es innegable que el éxito de un grupo teatral dependía también de las obras y de los autores escogidos. Las agrupaciones que actuaron durante la década eran todas de repertorio, y como buenas conocedoras de su público y de sus limitaciones ajustaron su lista de obra de forma práctica elaborando una nómina de escogidas y conocidas piezas del "más selecto teatro clásico y moderno", que completaron con una representativa y atractiva gavilla de novedades y obras a estrenar. Sin embargo, las largas estancias condicionaron más de una vez las buenas expectativas previas con malas interpretaciones, fruto de la falta de ensayos o de dificultades y limitaciones técnicas o humanas. A veces estas trabas provenían de las mismas empresas y se convertían en problemas insalvables que llevaban a las compañías a terminar antes de tiempo su temporada. Es lo que sucedió con los artistas de la compañía del maestro Villa, que no dieron la última función de abono en S. C. de Tenerife porque la empresa les adeudaba doce días de sueldo. Igual le ocurrió a la de Giovanni en Tenerife, que tuvo que suspender sus funciones por impago de la empresa; a la de Alaria, que desistió, según la prensa, de actuar en Gran Canaria por desavenencias entre los artistas (Sección de noticias, 1905, diciembre 29); y la de Valentín González, que se disolvió en Las Palmas de Gran Canaria a los tres días de llegar de S. C. de Tenerife, porque se le debían 6000 pts. y pico de su actuación en Tenerife (Sección de noticias, 1908, marzo 13).

Desde el inicio de la regularización de la actividad dramática en las islas, algunas de las compañías que nos visitaron pusieron en escenas obras de autores del país o de residentes en él. Se trataba, como resulta evidente, de un do ut des al que se avenían bien los grupos dramáticos, interesados en empatizar con el público y la crítica en aras de la taquilla, y los dramaturgos, deseosos de aprovechar las pocas oportunidades que tenían de ver sus piezas representadas por profesionales. Comparativamente, se puede afirmar que durante esta década que estudiamos este tipo de colaboración fue significativa, lo que unido también a una fructífera labor, en el mismo sentido, de los grupos de teatro de aficionados de sociedades como El Recreo y Santa Catalina, la sociedad teatral Los Doce, la Sociedad Filarmónica de Las Palmas, Círculo de Amistad, etc., hizo posible que la producción teatral canaria estrenada durante este periodo fuera bastante representativa, si bien, por la premura con la que se estrenaban estas piezas, no siempre su desempeño fue tan acertado como sus autores hubieran deseado. 
Por otro lado, debemos recordar que gran parte de estas obras tenían, entre otras, dos evidentes características que estaban también claramente relacionadas: eran lírico-dramáticas y estaban ambientadas en el suelo canario. El mayor peso de este tipo de producciones en el total de piezas canarias estrenadas durante la década es evidente, como los muestran los trabajos de Francisco Martínez Viera, Luis Alemany (1977), Carlos Brunetto, Isidoro Santana Gil (1999) y Salvador Martín Montenegro $(2010,2012)$. En este sentido, Brunetto, al aludir a la relevante presencia de obras cortas de esta naturaleza, afirmaba que nuestros artistas veían que el género chico exigía menor esfuerzo que la ópera o la zarzuela grande, "puesto que sólo se requería un libreto no muy pretencioso y unos cuantos números musicales", y hacía notar que si a la accesibilidad de estas piezas le sumamos "los valores nacionalistas canarios insertos en la sociedad [isleña] de la época, podremos entender [...]” esta elección de la zarzuela como medio de expresión "del supuesto casticismo canario, siguiendo [...] los moldes impuesto por los autores madrileños" (p. 59).

Esta menor complejidad facilitaba también su representación por las compañías a las que se presentaba la obra. Se puede decir que, "prácticamente todos los autores de libretos de zarzuelas canarias del género chico eran naturales de las islas, mientras que los compositores fueron, en varias ocasiones, los directores de la orquesta de la compañía que representaba por primera vez esa zarzuela. [...] demostrando con ello que el libreto fue escrito exprofeso para determinada compañía" (Brunetto, p. 60).

Sin embargo, para entender en su verdadera dimensión la importancia que en la década tiene el teatro de autores isleños, tanto en su vertiente costumbrista como renovadora, no debe olvidarse, como hemos indicado más arriba, la actividad de los grupos amateurs. Así, por poner un ejemplo revelador, hay que colocar en un lugar privilegiado a Santiago Tejera Ossavarry y a la Sociedad Filarmónica de Las Palmas de Gran Canaria ${ }^{25}$. A él y a ella se deben en esos años textos fundamentales del teatro lírico-dramático canario desempeñados por aficionados, que fueron en su momento para los espectadores y los críticos un hallazgo.

La primera troupe profesional de la década que representó una pieza de autor del país fue la de Julia Cirera, que en junio de 1901 puso en escena en S. C. de Tenerife, con Divorciémonos de Sardou, el monólogo en un acto Octavio del lanzaroteño Benito Pérez Armas. Se trataba de una reposición, pues la obra la había estrenado la Cía. de Sánchez de León en la misma ciudad en abril de 1899 y en Las Palmas de Gran Canaria en mayo del mismo año. La temporada 1901-02 la inició la Cía. de zarzuelas de Antonio Paso en Gran Canaria en octubre y en Tenerife en diciembre

${ }^{25}$ Para conocer la labor de esta sociedad resulta imprescindible el trabajo de Lothar Siemens Hernández (1995), Historia de la Sociedad Filarmónica de Las Palmas y de su Orquesta y sus Maestros, Las Palmas de G. C.: Sociedad Filarmónica de Las Palmas. 
de 1901. En ambas islas la agrupación dio a conocer piezas de autores isleños ${ }^{26}$. La primera fue la zarzuela de costumbres canarias La Última, letra del lanzaroteño Ángel Guerra y del tinerfeño Manuel Delgado Barreto, música del maestro grancanario Andrés García de la Torre, que se puso en escena en el Pérez Galdós (Tirso de Moli$n^{27}$ ) el 27-11-1901. Convenientemente refundida se reestrenó bajo el título de La copla el 5-2-1902 en el mismo coliseo por la compañía que sucedió a la de Antonio Paso, la de Pablo López. El 5-2-1902 estrenó en Tenerife La hija del bosque ${ }^{28}$, zarzuela en un acto y en prosa con música del maestro Santiago Lope $e^{29}$ y libreto de Mario Arozena.

Una de las novedades que llevaba la empresa en su repertorio era el sainete lírico en un acto El bateo, libreto del tinerfeño Antonio Domínguez ${ }^{30}$ y Antonio Paso, música de Federico Chueca, que se había estrenado en Madrid el 7-11-1901. Su puesta en escena se realizó en S. C. de Tenerife el 16-1-1902. En Las Palmas de Gran Canaria lo escenificaría la Cía. de Pablo López en junio de 1902 en el Pérez Galdós y en el Circo Cuyás (En el "Circo Cuyás", 1902, junio 30). También fue repuesto posteriormente, por lo menos, por la agrupación de Bonoris-Duval y por la de Valentín González.

Especial interés tiene la actuación de la de Pablo López (1901-03), que hizo posible, como pocas, que un buen número de piezas de libretistas y compositores isleños se pusieran sobre el escenario: la ópera en un acto Rosella, compuesta por Andrés García de la Torre, letra de Cesare Alberto Blengini; la zarzuela La copla con letra de Ángel Guerra y Delgado Barreto, música de Andrés García de la Torre; la zarzuela en tres actos del maestro Bernardino Valle La perla negra con letra de su mujer Joaquina Gracia (Santana Gil, 1999: 565); la zarzuela en un acto y tres cuadros, y en prosa de Mario Arozena, música de Andrés García de la Torre, Ángela; la zarzuela en un acto Alegría (Martín Montenegro, 2010: 134) de los tinerfeños Emilio Saavedra (Fernando Suárez y G. Corvo) y Domingo J. Manrique con música del maestro Ricardo Sendra; La hija de Robespierre, zarzuela en tres actos, letra de Cirilo Moreno

${ }^{26}$ La compañía estrenó también la zarzuela de costumbres canarias La Virgen de la Luz, letra del granadino Antonio Paso y música del riojano Santiago Lope. La obra fue escrita a vuela pluma poco antes de representarse en el Pérez Galdós el 2-12-1901. Se estrenó en Tenerife el 2-2-1902. Se imprimió en 1903 y se representó, que sepamos, en Madrid, Sevilla, México y La Habana.

${ }^{27}$ Con motivo del estreno de Electra en 1901 el coliseo fue rebautizado como Teatro Pérez Galdós.

${ }^{28}$ Sería editada el mismo año, como la zarzuela Ángela del mismo autor, en la Imprenta de Anselmo J. Benítez.

${ }^{29}$ Santana Gil (1999: 554) afirma que Santiago Lope compuso la música de una revista de cuadros canarios titulada La huelga, letra de Antonio Paso y Antonio Domínguez, que se programó para la temporada de invierno 1901-1902, aunque no tiene noticias de su estreno.

${ }^{30}$ Además de esta pieza, Antonio Domínguez estrenó en estos años en el Teatro de la Zarzuela de Madrid los sainetes líricos El ciego de Buenavista (1904), música de Tomás L. Torregrosa, y El seductor (1905), música de Ruperto Chapí. 
y música de Segundo Manchado Medina; El Cristo de La Laguna drama lírico en 3 actos de Rafael Vilela y Montesoro ${ }^{31}$, verso de Fernando Suárez y G. Corvo, música de los maestros Ricardo Sendra y Braulio Gonzálvez; el monólogo El penitente del tinerfeño Leoncio Rodríguez; la zarzuela en dos actos de Fernando Suárez y G. Corvo Por amor y por dinero, escrita expresamente para el tenor Ristorini; la zarzuela en un acto de costumbres del país De la tierra canaria, letra de Mario Arozena y Diego Crosa y Costa, música de José Crosa; y la zarzuela Trinidad libreto de Manuel Pastor Plazas, quien dio permiso al periódico El Atlántico para que lo publicase en folletín (Santana Gil, 1999: 572) y música de José Hernández Sánchez ${ }^{32}$.

La estela de Antonio Paso y de Pablo López se mantuvo en los años inmediatos, aunque no con el mismo vigor, con la visita de la compañía de Sánchez de León, que en su estancia en S. C. de La Palma escenificó La pena de muerte ${ }^{33}$, drama en verso del palmero Antonio Rodríguez López (Rey y Abdo, 1984, 25). La de Emilio Thuillier que presentó, primero en el Pérez Galdós (6-5-1903) y poco después en el Principal de S. C. de Tenerife (28-5-1903), La herencia de Araus, drama en tres actos de Luis y Agustín Millares $\mathrm{Cubas}^{34}$, que por su posición dentro de la renovación de la dramaturgia española o porque no pasó desapercibida para los espectadores, sorprendió seguramente a los propios autores isleños interesados en el regionalismo literario y en crear una identidad por medio de temas y ambientes locales. González Díaz (1902, noviembre 26), afirmaba al respecto, tras el estreno de La hija del mestre, de forma clara: "Cunde la manía de escribir dramas líricos regionales. El maestro Tejera, sin quererlo, va a traer sobre el país una terrible plaga. Antes de que se escribiera Folías tristes, se iniciaba la epidemia; hoy, después de Folías y de La hija del mestre, el contagio toma carácter agudo" (Martín Montenegro, 2010: 137-8, 140-1).

Por su parte, la de Aranaz-Echaide presentó el "cuadro psíquico dramático" Luchas del alma de Mario Arozena en el Teatro Principal de la capital tinerfeña el 10-5-1904. La de Donato Jiménez estrenó la comedia en 1 acto de los hermanos Millares Tan cerca y tan lejos el 31-3-1906 junto con un acto de Amor y Ciencia de Pérez Galdós y otro de Tierra baja de Ángel Guimerá en el Pérez Galdós en la función de gala ofrecida en honor de los reyes. La de García-Nieva representó un

${ }^{31}$ Rafael Vilela también compuso el libreto de la zarzuela María de la Luz (González Díaz, 1904, septiembre 20).

${ }^{32}$ Según la prensa (Sección de noticias, 1903, enero 7; Crónica, 1903, enero 2) la compañía había distribuido los papeles y comenzado los ensayos de la zarzuela Martirios, libro de Mario Arozena y música del maestro Sendra. No sabemos si se representó. Tampoco tenemos noticia de la posible puesta en escena de la revista cómico-lírica en un acto y tres cuadros Exposición canaria, letra de Manuel Pastor, música de Juan Daranas, que se anunció que estrenaría la Cía. de Pablo López (Sección de noticias, 1902 noviembre 10; Santana Gil, 1999: 574).

${ }^{33}$ Ha sido editada en unión de dos piezas más del autor, El ciprés de la sultana y La cruz de rubies (intr. de Antonio Abdo, ed. de Antonio Tabares, S. C. de La Palma, Cabildo Insular, 2001).

${ }^{34}$ Se estrenó en el Teatro Cervantes de Málaga el 5-1-1903. 
juguete cómico de Casto Martínez en el Circo Cuyás (Sección de noticias, 1907, octubre 4) y La muerta del palmero Manuel Reyes Díaz en S. C. de la Palma (Rey y Abdo, 1984, 26). La de Cobeña estrenó en febrero de 1909 en el Pérez Galdós y en marzo en el Principal la comedia de los hermanos Millares María de Brial ${ }^{35}$.

Por otro lado, en esta línea, pero en otro orden, no debemos olvidar el interés de las compañías por la puesta en escena de las obras de dos notorias personalidades de las letras y de los escenarios. Nos referimos a Benito Pérez Galdós y Ángel Guimerá. En Canarias, al de por sí abrumador prestigio de ambos, se sumaba el de su paisanaje, que las empresas teatrales intentaban rentabilizar reponiendo textos conocidos o, en su caso, estrenando obras no representadas, en especial las últimas novedades. Así, por ejemplo, el hecho de que la Cía. de Donato Jiménez en la velada ofrecida a sus majestades en su visita a Las Palmas de Gran Canaria organice un programa con Galdós, Guimerá y los hermanos Millares viene a ilustrar el valor seguro y representativo de estos nombres.

La primera compañía que puso en escena en esta década piezas de estos dos autores fue la de Julia Cirera, que representó en marzo de 1901 en el Tirso de Molina, y en mayo y junio del mismo año en el Teatro Principal de S. C. de Tenerife, el drama de Ángel Guimerá El padre Juanico. La pieza era aún recordada por los espectadores, pues la había presentado aquí la Cía. de Manuel Espejo en 1899 (López Cabrera, 1995a: 129). Sin embargo, la verdadera novedad fue el estreno de Electra de Pérez Galdós en Las Palmas de Gran Canaria el 16-4-1901 y en S. C. de Tenerife el 22 de mayo. Al igual que la de Cirera, muchas de las compañías dramáticas de este periodo, v. gr., las de Sánchez León, Aranaz-Echaide, Donato Jiménez, Ricardo Calvo, Enrique Borrás, y Cobeña, como otras antes (López Cabrera, 1995a, 1995b), incluyeron en sus repertorios obras de estos dos escritores, de las que nos constan, además de las citadas: El abuelo, Mariucha, La loca de la casa, Amor y ciencia, Alma y vida, La de San Quintín, Mar y cielo, Tierra baja, Agua que corre y María Rosa.

${ }^{35}$ La Cía. de Salvador Orozco puso en escena el 15 de febrero de 1910 la revista cómicolírica en un acto y cinco cuadros, en prosa y verso, cuyo último cuadro se desarrolla en Santa Cruz de Tenerife, Viaje de... primos de los "aplaudidos autores residentes en la localidad" Luis Constante Moya (militar de profesión) y Julián Fuentes (actor de la compañía), libretistas, y Pedro Sugránez, maestro director y concertador de la compañía, creador de la música. En la edición impresa de la obra (Madrid, R. Velasco, 1912), que recoge el texto estrenado el 12 de Agosto de 1912 por la compañía de Julio Ruiz y José Ontiveros en el Teatro de la Latina, la pieza solo tiene cuatro cuadros y el último transcurre en Sevilla. De Luis Constante Moya se conocen, entre otras, las siguientes obras: El fonocromoscop (1903), revista cómico-lírica en un acto, siete cuadros, doce vistas y dos intermedios, letra de Rafael Abellán y Luis Constante, música de Eduardo G. Arderius y Luis Foglietti. El murguista (1903), zarzuela en un acto, cuatro cuadros, en prosa y verso, letra de Rafael Abellán y Luis Constante, música de Eduardo G. Arderius. El grito de la conciencia (1904), boceto dramático en un acto y en verso, de Rafael Abellán y Anta y Luis Constante. Princesita Blanca (1925), apunte de opereta en un acto, tres cuadros, en prosa y verso, música de Francisco Calés y Manuel Sancha. 
Se puede decir que a comienzos del siglo Xx el teatro, como actividad de recreo, de ocio y de cultura, disfrutaba de una posición de importancia junto a otras actividades de entretenimiento también relevantes como las luchadas, las peleas de gallos, las actuaciones de las bandas de música, las veladas culturales y festivas, los bailes y los paseos. El teatro, como es sabido, se había consolidado en esta posición poco a poco desde finales del primer tercio del siglo XIX, gracias a la llegada frecuente de compañías de cómicos profesionales, que hicieron posible la regularización de la actividad dramática, es decir, la existencia de teatros y de temporadas teatrales (Martínez Viera, 1968; Martín Montenegro, 1991, 1995; López Cabrera, 1995; Fuentes Pérez, 2012).

Nada hacía pensar, por tanto, que un quindenio después esa situación habría de cambiar de manera drástica gracias al desarrollo del cinematógrafo y, de tal modo, que la actividad dramática quedaría relegada, desde el punto de vista de su popularidad, a una posición menos influyente. Una situación que, en vez de modificarse, iría en aumento con la presencia de otro divertimento público, el deporte. Sin embargo, en los primeros compases de la primera década del siglo, la principal competencia del teatro estaba en las variedades y en el "teatro ínfimo". Aún el cine no era un serio rival, pues, a lo sumo, se le consideraba como parte de esas variedades. No obstante, su presencia en las carteleras al correr la década fue cada vez mayor, consolidándose como un entretenimiento demandado, que coadyuvó además al auge de las variedades y, paradójicamente, también al del teatro, el cual elevó el número de sus espectadores gracias a la construcción de nuevos edificios teatrales: pabellones, parques y circos. Lo que sucede a partir de la segunda década es que de manera progresiva el público del teatro disminuye, pero solo si se le compara con el que el que va a los cines y a los espectáculos deportivos, especialmente el fútbol, y no porque estas actividades hayan detraído espectadores al teatro, sino porque recogieron a una buena parte del público posible, más popular, que no podía o no iba al teatro por razones económicas, por la inexistencia en muchos lugares de espacios adecuados y representaciones regulares, o simplemente por cuestión de gusto.

\section{REFERENCIAS BIBLIOGRÁFICAS}

A. R. (1908, mayo 18). Desde Arrecife. La Opinión, p. 2.

- (1908, mayo 29). Desde Arrecife. La Opinión, p. 1.

— (1908, junio 6). Desde Arrecife. La Opinión, p. 1.

— (1908, junio 22). Desde Arrecife. La Opinión, pp. 1-2.

(1908, junio 30). Desde Arrecife. La Opinión, p. 1.

Alemany, L. (1977): Repertorio teatral canario. Catálogo espectacular y bibliográfico de la literatura dramática escrita por autores de las islas Canarias [Inédito].

Castro Brunetto, C. (1990): La música en Tenerife después de la Sociedad Musical «Santa Cecilia» (1900-1931), [Memoria de Licenciatura inédita], Universidad de La Laguna, La Laguna.

La compañía dramática de Carmen Cobeña (1909, enero 11). Diario de Las Palmas, p. 2. 
El Corresponsal (1907, julio 27). Desde Arrecife. Diario de Tenerife, p. 3.

Crónica (1901, noviembre 16). Cronista de Tenerife, p. 3.

- (1902, octubre 23). Diario de Tenerife, p. 2.

(1903, enero 2). Diario de Tenerife, p. 2.

(1903, enero 9). Cronista de Tenerife, p. 2.

Crónica. Teatral (1902, octubre 18). La Opinión, p. 2. (1902, octubre 27). La Opinión, p. 2.

Crónica general. Artistas (1906, febrero 26). El Progreso, p. 2.

Crónica general. De teatros (1907, diciembre 5). El Progreso, p. 2.

Crónica general. Teatral (1907, diciembre 4). El Progreso, p. 2.

Crónica general. Teatro principal (1908, mayo 5). El Progreso, p. 2.

Crónica general. Viajeros (1907, diciembre 10). El Progreso, p. 2.

De teatro. La compañía de Borrás (1908, febrero 2). La Opinión, p. 1.

En el Circo (1907, marzo 6). Diario de Las Palmas, p. 2.

En el “Circo Cuyás” (1902, junio 30). Diario de Las Palmas, p. 2.

Espectáculos (1907, enero 10). Diario de Las Palmas, p. 2.

—_ (1907, marzo 22). La Opinión, p. 1.

La Filarmónica. Cuadro de zarzuela (1905, noviembre 22). La Opinión, p. 2.

Fray Gerundio (1908, febrero 1). Teatro. La Opinión, p. 2.

Fuentes Pérez, G. (2012): «El Coliseo-Bodega de la calle La Marina en Santa Cruz de Tenerife», Latente 10: 153-173.

GonzÁlez Díaz, F. (1902, noviembre 26): Dramático-manía. Diario de Las Palmas, p. 1. (1904, septiembre 20): María de la Luz. Una lectura. Diario de Las Palmas, p. 1.

(1905, noviembre 4): Educación artística. Diario de Las Palmas, p. 1.

Hernández, M. a V. (2001, agosto 5): El teatro en Los Llanos de Aridane /1. Diario de Avisos, p. 24.

HeRNÁNDEZ Bravo, R. (2005): «Notas para un estudio de la actividad teatral en el Valle de Aridane, Isla de La Palma, (1778-1924)", Revista de Estudios Generales de la Isla de La Palma 1: 237-253.

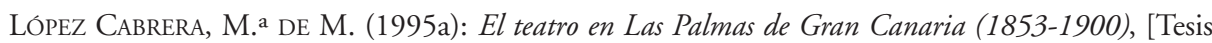
doctoral], Universidad Nacional de Educación a Distancia, Madrid [= 2003: Ed. impresa, Fundación Universitaria Española, Madrid].

_ (1995b): «El teatro de Galdós representado en Las Palmas de Gran Canaria durante los últimos años del siglo XIX», en Actas del V Congreso Internacional de Estudios Galdosianos, 1992 (v. II, pp. 325-332), Cabildo Insular de Gran Canaria, Las Palmas.

LuZardo Cabrera, D. M.a (2015): La temporada teatral de la Compañia de Manuel Espejo en Tenerife (17-VI/22-VII-1894), [Trabajo de Fin de Grado], Universidad de La Laguna, La Laguna <https://riull.ull.es/xmlui/handle/915/1332>.

Martín Montenegro, S. F. (1991): "Cartelera teatral canaria, 1832-39», en Homenaje a Sebastián de la Nuez Caballero, Universidad de La Laguna, La Laguna, pp. 145-163.

_ (1995): «Comedias, teatros y comediantes en Canarias (1833-1849)», en I Congreso de Historia y Crítica del Teatro de Comedias, Fundación Pedro Muñoz Seca/Ayuntamiento, El Puerto de Santa María, Cádiz, pp. 288-308. 
- (2010): «Representaciones de dramaturgos y compositores canarios en Canarias (1900-01/1904-05)», en Homenaje a Eduardo Camacho, Universidad de La Laguna, La Laguna, pp. 127-141.

(2012): «La compañía de Antonio Paso Cano y tres piezas del país (1901-1902)», en La Luz no interrumpida. Homenaje a Eugenio Padorno, Ediciones Clásicas, Madrid, pp. 121-133.

Martínez Viera, F. (1968): Anales del teatro en Tenerife, Editorial Católica, Santa Cruz de Tenerife.

Por la Provincia. De La Palma (1908, marzo 14). La Opinión, p. 1.

Los que viajan (1907, julio 13). La Opinión, p. 2.

— (1908, agosto 25). La Opinión, p. 2.

Rey, P. y Abdo, A. (1984): «Una aproximación al teatro en La Palma hasta 1936», en El Teatro en Santa Cruz de La Palma, Ayuntamiento, S. C. de La Palma, pp. 17-32.

SANTANA GIL, I. (1999): «Primera aproximación a las zarzuelas y óperas canarias producidas en los siglos XIX y XX», El Museo Canario 54(2): 537-597.

Sección de noticias (1900, marzo 13). Diario de Las Palmas, p. 2.

- (1902, noviembre 10). Diario de Las Palmas, p. 2.

- (1903, enero 7). Diario de las Palmas, p. 3.

- (1905, diciembre 29). Diario de Las Palmas, p. 2.

- (1907, octubre 4). Diario de Las Palmas, p. 2.

- (1907, marzo 10). Diario de Las Palmas, p. 2.

— (1907, noviembre 26). Diario de Las Palmas, p. 2.

- (1908, enero 11). Diario de Las Palmas, p. 2.

— (1908, enero 20). Diario de Las Palmas, p. 2.

(1908, marzo 13). Diario de Las Palmas, p. 2.

Teatral (1902, octubre 28). El Imparcial de Canarias, p. 2.

Teatrales. La compañía de Borrás (1908, enero 4). Diario de Las Palmas, p. 2.

Teatro (1910, febrero 24). La Opinión, p. 2.

La temporada teatral (1907, septiembre 2). El Tiempo, p. 2.

Varias noticias (1907, diciembre 23). La Opinión, p. 2.

- (1908, febrero 26). La Opinión, p. 2.

- (1908, marzo 27). La Opinión, p. 2. 